\title{
Educação Infantil e avaliação institucional: percursos e desafios
}

\section{Early Childhood Education and institutional evaluation: pathways and challenges}

\section{Educación Infantil y evaluación institucional: percursos y desafíos}

\author{
Maria Nilceia de Andrade Uieira ${ }^{1}$ \\ Universidade Federal do Espírito Santo (UFES), Integrante do Grupo de Pesquisa Formação e \\ Atuação de Educadores (GRUFAE) \\ Ualdete Côco² \\ Universidade Federal do Espírito Santo (UFES), Professora do Programa de Pós- \\ Graduação em Educação
}

Resumo: A trajetória da educação brasileira reúne embates que, em distintos momentos, acentuaram a exigência de enfrentamentos, repercutindo em conquistas no campo das políticas públicas. Focalizando o período das últimas quatro décadas, neste texto tem-se como propósito evidenciar questões relevantes acerca da trajetória da Educação Infantil e da avaliação institucional no Brasil. Ancorado em pressupostos teórico-metodológicos bakhtinianos e elaborado em uma perspectiva de pesquisa teórica, o presente artigo dialoga com produções científicas, ordenamentos legais e documentos orientadores publicados entre 1970 e 2017. As análises desses vestígios escritos indicam que a alteração dos rumos da primeira etapa da educação básica vem se consolidando em movimentos de disputa, e esses acontecimentos históricos demarcam posicionamentos de resistência e possibilidades de avanços. No que tange à avaliação institucional na Educação Infantil, a sistematização deste estudo explicitou que o panorama atual, decorrente de inúmeros fatos históricos, não se constitui exclusivamente o bojo das questões educacionais e se encontra circunscrito à história das crianças, das famílias trabalhadoras, da formação docente, das políticas públicas, de determinantes econômicos

\footnotetext{
Mestre em Educação pela Universidade Federal do Espírito Santo; Doutoranda em Educação pelo Programa de Pós-graduação em Educação do Centro de Educação da Universidade Federal do Espírito Santo

2 Doutora em Educação pela Universidade Federal Fluminense; Mestre em Educação pela Universidade Federal do Espírito Santo.
} 
e sociais, entre outros elementos. Conclui-se, portanto, que na interlocução da avaliação institucional com a Educação Infantil não se pode prescindir da qualidade socialmente referenciada, e, nessa direção, um dos desafios postos é a consolidação de sistemáticas avaliativas vinculadas a dinâmicas participativas e às condições do que ofertamos às crianças em seu processo educativo.

Palavras-chave: Educação pública. Educação Infantil. Avaliação institucional. Direitos das crianças.

Abstract: The trajectory of Brazilian education brings together strikes that, at different moments, accentuated the demand for confrontations, reverberating in conquests in the field of public policies. Focusing on the period of the last four decades, this text aims to highlight relevant issues about the trajectory of Early Childhood Education and institutional evaluation in Brazil. Anchored in Bakhtinian theoretical and methodological assumptions and elaborated in a theoretical research perspective, the present article dialogues with scientific productions, legal orders and guiding documents published between 1970 and 2017. Analyzes of these written traces indicate that the change in the directions of the first stage of education has been consolidating itself in movements of dispute and these historical events mark positions of resistance and possibilities of advances. Regarding the institutional evaluation in Early Childhood Education, the systematization of this study made it clear that the current panorama, arising from many historical facts, is not exclusively a matter of educational issues, and is limited to the history of children, working families, teacher education, public policies, economic and social determinants, among other elements. It is concluded, therefore, that in the interlocution of the institutional evaluation with the Early Childhood Education, one can not do without the socially referenced quality and, in this direction, one of the challenges posed is the consolidation of evaluation systems linked to participatory dynamics and the conditions of which we offer children in their educational process.

Keywords: Public education. Early Childhood Education. Institutional evaluation. Rights of children.

Resumen: La trayectoria de la educación brasileña reúne embates que, en distintos momentos, acentuaron la exigencia de enfrentamientos, repercutiendo en conquistas en el campo de las políticas públicas. Enfocando el período de las últimas cuatro décadas, este texto tiene como propósito evidenciar cuestiones 
relevantes acerca de la trayectoria de la Educación Infantil y de la evaluación institucional en Brasil. En el presente artículo dialoga con producciones científicas, ordenamientos legales y documentos orientadores publicados entre 1970 y 2017. Los análisis de estos vestigios escritos indican que la alteración de los rumbos de la primera etapa de la educación básica se viene consolidando en movimientos de disputa y esos acontecimientos históricos demarcan posicionamientos de resistencia y posibilidades de avances. En lo que se refiere a la evaluación institucional en la Educación Infantil, la sistematización de este estudio explicitó que el panorama actual, derivado de innumerables hechos históricos, no se constituye exclusivamente en el seno de las cuestiones educativas, y se encuentra circunscrito a la historia de los niños, de las familias trabajadoras, formación docente, de las políticas públicas, de determinantes económicos y sociales, entre otros elementos. Se concluye, por lo tanto, que en la interlocución de la evaluación institucional con la Educación Infantil, no se puede prescindir de la calidad socialmente referenciada y, en esa dirección, uno de los desafíos planteados es la consolidación de sistemáticas evaluativas vinculadas a dinámicas participativas ya las condiciones de lo que ofrecemos a los niños en su proceso educativo.

Palabras clave: Educación pública. Educación Infantil. Evaluación institucional. Derechos de los niños.

\section{INTRODUÇÃO}

A trajetória da educação pública brasileira se constitui em interlocução com a efetivação de medidas políticas, econômicas e sociais, com o desenvolvimento de pesquisas científicas e produções acadêmicas e com a mobilização de entidades da sociedade civil. Considerando o contexto da educação básica e especialmente o campo da Educação Infantil na observação do recorte dos últimos 40 anos, constatamos um percurso demarcado por disputas, debates, conquistas, retrocessos e lutas que buscam incidir na elaboração de políticas públicas relativas a temas mantidos em pauta nas discussões coletivas e no quadro de reivindicações atuais. 
Assentes na perspectiva de que nossa formação humana se atrela às relações dialógicas com o outro em relação ao meio social concreto que nos envolve (BAKHTIN, 201 l), reconhecemos que a compreensão e a apropriação dos eventos que nos propomos a analisar estão interligadas à nossa história, ou seja, à nossa visão de mundo, ao nosso ponto de vista. Entretanto, esse processo de assimilação não deve se manter inalterado, considerando que "[...] o sujeito da compreensão não pode excluir a possibilidade de mudança e até de renúncia aos seus pontos de vista e posições já prontos. No ato da compreensão desenvolve-se uma luta cujo resultado é a mudança mútua e o enriquecimento." (BAKHTIN, 201 1, p. 378).

Com essa compreensão, que marca o movimento do pensamento na produção de sentidos para os eventos, organizamos essa interlocução em quatro movimentos, além da introdução e das considerações finais. No escopo dos últimos 40 anos da educação pública brasileira, com atenção à etapa inicial da educação básica, apresentamos, logo após esta introdução, os pressupostos teórico-metodológicos, situando a avaliação institucional e a Educação Infantil, com vistas a compor uma breve abordagem conceitual e histórica. Como segundo movimento dialógico, pontuando fatos e estudos significativos anteriores à Constituição Federal (BRASIL, 1988), demarcamos o contexto político do Regime Militar e a organização de educadores e pesquisadores pela universalização da escola pública de educação básica, que ainda não incluía o atendimento às crianças menores de sete anos. Na sequência, a partir dos avanços na legislação após a promulgação da Constituição Federal, destacamos conquistas e desafios que se mantêm na área da Educação Infantil. No quarto movimento, focalizamos o percurso da avaliação institucional nessa etapa, em relação a pesquisas desenvolvidas e documentos oficiais publicados. $\mathrm{Na}$ continuidade do diálogo, compartilhamos nossas considerações finais com um convite às contrapalavras, destacando a necessária articulação da avaliação com a qualidade da Educação Infantil.

Com essa organização delineada, seguimos nosso movimento dialógico, situando teórica e metodologicamente a Educação Infantil e a avaliação institucional. 


\section{PRESSUPOSTOS TEÓRICO-METODOLÓGIICOS}

No enfoque diretivo deste texto, situamos a Educação Infantil nos processos de transformação ao longo de sua trajetória (ROSEMBERG, 2003). ressaltando seu reconhecimento como direito das crianças e de suas famílias (BRASIL, 1988) e como primeira etapa da educação básica (BRASIL, 1996) a ser ofertada "[...] em espaços institucionais não domésticos que constituem estabelecimentos educacionais públicos ou privados que educam e cuidam de crianças de 0 a $5^{3}$ anos de idade [...]" (BRASIL, 2009b). Nessa condição de pertencimento ao sistema de ensino brasileiro, as mudanças operadas no conjunto desse sistema impactam a Educação Infantil, demarcando o desafio pelo reconhecimento de sua especificidade nesse âmbito mais amplo.

Circunscrevendo as questões avaliativas como parte da temática deste artigo, consideramos a origem etimológica da palavra "avaliar", que provém da composição a-valere (latim) e significa "dar valor a". Desse modo, valorar ou valorizar algo faz parte de muitas atividades humanas como ações implícitas no nosso cotidiano em variadas situações, muitas vezes sem a necessidade de formalidades, registros e análises.

Ao focalizar o campo educacional, Dias Sobrinho (2003) esclarece que as diferentes concepções de avaliação resultam de transformações sociais oriundas das escolhas feitas em determinados momentos históricos, ultrapassando a dimensão pessoal para influenciar o contexto mais amplo da sociedade. Afirma que a avaliação vem sendo objeto de interesse das políticas de governo, das agências e organismos que atuam na estruturação e gestão do setor público e, em especial, da educação.

\footnotetext{
3 Embora essa questão seja abordada na próxima seção, cabe aqui esclarecer que, com a ampliação do Ensino Fundamental para nove anos, determinada pela Lei n. 1 1.247/2006, a Educação Infantil passa a atender às crianças de até cinco anos, conforme estabelece a Emenda Constitucional n. 53, de 19 de dezembro de 2006. Contudo, a Educação Infantil também atende a crianças de seis anos, tendo em vista o que prevê a Resolução MEC/SEB n. 5/2009, que fixa a data limite de 31 de março para matrícula conforme a idade, o que implica o atendimento de crianças dessa faixa etária no decorrer dos meses seguintes a essa data.
} 
Em relação à Educação Infantil, Rosemberg (2003) acentua a configuração da avaliação como um "problema social" recentemente incluído nas pautas das políticas públicas, embora seja uma prática já desenvolvida na primeira etapa da educação básica e direcionada às crianças sob a responsabilidade de outras áreas, como a Psicologia.

Com base em concepções bakhtinianas, valorizamos o contato com enunciados que nos antecedem, por acreditar que somos simultaneamente ouvintes e falantes, e "[...] cada enunciado é um elo na corrente complexamente organizada de outros enunciados." (BAKHTIN, 201 1, p. 272). Assim, buscando participar dessa teia dialógica, no escopo temático selecionado para este texto, integramos os estudos que afirmam a avaliação institucional em articulação com a qualidade da Educação Infantil na perspectiva dos direitos das crianças. Para isso, interagimos com ideias defendidas por pesquisadores atuantes no cenário educacional brasileiro (CAMPOS et al., 201 1, CAMPOS, 2013; KRAMER, 1995, 2006; MORO; SOUZA, 2014; ROSEMBERG, 2001, 2003, 2013) que assumem o enfrentamento às ameaças impostas pelas políticas em andamento as quais colocam muitas de nossas "conquistas em risco" (ASSOCIAÇÃ $\bigcirc$ NACIONAL DE PÓS-GRADUAÇÃO E PESQUISA EM EDUCAÇÃO, 2016), no que concerne à consolidação de avanços alcançados nas últimas décadas.

Em interlocução com a abordagem histórica, recorremos a Bloch (2002), quando assevera que o historiador precisa estabelecer relações entre passado e presente e atentar para a ação do homem no contexto histórico e no espaço-tempo. Ao expor a necessidade de uma história mais humanizada, o autor nos instiga a analisar os eventos, problematizando sua construção histórica para além da linearidade temporal.

Nesse sentido, cabe observar, no entanto, que há limites para essa problematização. Como destaca o autor, os registros que acessamos se configuram como recortes, e a utilização desses vestígios possibilita variadas visões sobre o passado, pois se referem a fatos que não vivenciamos diretamente. Assim, as divisões cronológicas dos acontecimentos conformam um contexto já dado, ou seja, o material definido para estudo foi construído por meio de várias seleções consecutivas, sendo importante ao historiador essa compreensão diante da decisão de investigação histórica (BLOCH, 2002). 
No encadeamento de nossas palavras, avançamos para o campo ampliado do atendimento às crianças pequenas no âmbito da educação em nosso País antes da Constituição Federal (BRASIL, 1988).

\section{OS MOUIMENTOS EM DEFESA DA ESCOLA PÚBLICA NAS DÉCADAS DE $1970 \mathrm{E} 1980$}

Ao nos inserirmos em discussões acerca da trajetória da Educação Infantil no Brasil, consideramos improvável abordar essa temática apartada do contexto mais amplo da educação nacional e do cenário político do País. Assim, assinalamos a conjuntura política marcada pelo regime autoritário da Ditadura Civil-Militar, com o golpe de Estado de 1964, que marcou o início de um período em que as possibilidades de reivindicações por movimentos populares eram duramente reprimidas.

Essa conjuntura apresentou sinais de mudança desde os anos 1970, configurando um período marcado tanto por lutas da sociedade civil organizada em busca do fim da Ditadura Militar quanto pela redemocratização política do Brasil. Nessa época, vários acontecimentos econômicos e políticos, com influências da conjuntura internacional, concentraram-se em 1985. contribuindo para o fim desse Regime (RUIZ, 2013).

Desde meados da década de 1970 ocorriam insatisfações e manifestações populares. $\bigcirc$ movimento estudantil, desde 1976, organizava seus protestos contra a ditadura. A Sociedade Brasileira para o Progresso da Ciência (SBPC) congregava vários intelectuais que faziam da universidade um espaço de resistência. As grandes greves dos metalúrgicos, nos anos de 1978 e 1979, marcaram a retomada da força da classe trabalhadora, que almejava melhorias salariais e a ampliação da participação política. (RUIZ, 2013, p. 241).

Assim, a organização de educadores e pesquisadores se fortaleceu em defesa da universalização da escola pública, com reivindicações pela construção 
e manutenção de creches pelo poder público, visando ampliar o número de vagas na Educação Infantil. No âmbito da legislação, mediante a Lei n. 5.692 (BRASIL, 1971), conhecida como a Lei da Reforma do Ensino, fica disposto que as crianças menores de sete anos podem receber educação nas escolas maternais, jardins de infância ou instituições equivalentes, com a previsão de três anos de escolaridade para crianças de quatro a seis anos de idade.

No sentido de traçar uma trajetória do modelo de educação préescolar, implantado durante o período do Regime Militar e desenvolvido até a abertura política de meados da década de 1980, Rosemberg (1992, p. 26) afirma que "Apesar de ter formulado um programa nacional de educação pré-escolar de massa, não foi o MEC que conseguiu implantá-lo na década de 1970, mas sim a Legião Brasileira de Assistência (LBA), através do Projeto Casulo." De acordo com a autora, essa proposta elaborada pelo MEC em 1975 tornou-se o modelo nacional de atenção ao pré-escolar, sendo retomada pela LBA, ultrapassando o Governo Geisel e chegando à gestão do Governo Figueiredo, sendo revisitada, em 1988, pelo Ministro Hugo Napoleão. No que se refere às formas de atendimento às crianças pequenas, esse modelo deixou como influências:

\begin{abstract}
[...] a possibilidade de intervenção federal através de programas, o que efetivamente ocorreu na gestão do Gal Figueiredo e durante a Nova República; a divulgação da ideia [sic] da pré-escola nas administrações educacionais locais; a criação de uma instância específica nas administrações federal e estaduais. (ROSEMBERG, 1992, p. 26).
\end{abstract}

Em meio a essas ações, intensificam-se os debates sobre a educação das crianças menores de sete anos, como possibilidade de melhoria de suas condições, sem, contudo, pensar em alterar as estruturas sociais que geravam os problemas desse atendimento. Tal descompasso era alvo de recomendações de Florestan Fernandes, que defendia que as questões educacionais deveriam se pautar no "[...] debate sobre as políticas socioeconômicas implementadas nos últimos anos - o que, por sua vez, determina qual o papel do estado na 
promoção dos direitos fundamentais do homem, no qual está incluso o acesso à educação [...]" (OLIVEIRA, 2010, p. 108).

Sobre essa questão, Kramer ( 1995) aponta que a defesa do atendimento às crianças das classes menos favorecidas pelo poder público se baseia em uma concepção de infância que concebe esse período da vida da criança de maneira padronizada e homogênea. A ideia é que as crianças oriundas das classes sociais dominadas são "[...] carentes, deficientes e inferiores na medida em que não correspondem ao padrão estabelecido; faltariam a essas crianças, privadas culturalmente, determinados atributos ou conteúdos que deveriam ser nelas incutidos." (KRAMER, 1995, p. 24).

Por esse motivo, visando superar as deficiências de saúde e nutrição, assim como as deficiências escolares, no intuito de compensar tais carências, a pré-escola também funcionaria, segundo a autora, como mola propulsora da mudança social, uma vez que possibilitaria a democratização das oportunidades educacionais.

Ambas as funções podem ser desmistificadas. Ao nível da
primeira função, considera-se a educação como promotora
da melhoria social, o que é uma maneira de esconder
os reais problemas da sociedade e de evitar a discussão
dos aspectos políticos e econômicos mais complexos.
A proposta que ressurge de elaborar programas de
educação pré-escolar a fim de transformar a sociedade
no futuro é uma forma de culpar o passado pela situação
de hoje e de focalizar no futuro quaisquer possibilidades
de mudança. Fica-se, assim, isento de realizar no presente
ações ou transformações significativas que visem a atender
às necessidades sociais atuais. (KRAMER, 1995, p. 30).

Ao considerarmos o percurso histórico de defesa do atendimento à infância, observamos a atuação de movimentos estudantis, sociais, sindicais, das famílias, das feministas, de professores e pesquisadores com questões que permanecem em pauta nos caminhos mais recentes da Educação Infantil. Kuhlmann Júnior (2000), ao fazer referência a esse quadro de embates, principalmente desde a década de 1970, assinala as discordâncias e confrontos em relação a concepções educacionais e familiares, instituição, assistência, 
puericultura, higiene, jogos, brincadeiras, desenvolvimento, cognição e recreação. Cabe ressaltar que já se demarcava uma arena de disputas que, além das concepções, incluía a própria finalidade das instituições que

[...] tanto eram propostas como meio agregador da família para apaziguar os conflitos sociais, quanto eram vistas como meio de educação para uma sociedade igualitária, como instrumento para a libertação da mulher do jugo das obrigações domésticas, como superação dos limites da estrutura familiar. (KUHLMANN JÚNIOR, 2000, p. 11).

Esse contexto de disputas traz à tona elementos que nos ajudam a compreender o cenário atual da Educação Infantil com as lutas, controvérsias e tensões que o integram. Nesse quadro mais recente, destacamos, na legislação, ${ }^{4}$ alguns avanços significativos com a aprovação de leis e a elaboração de documentos que ampliam essas bases legais, orientam e normatizam as políticas públicas para a infância.

É importante considerar que os avanços na legislação direcionada à Educação Infantil decorrem, em muitas situações, das reivindicações manifestadas pelas diversas entidades ligadas aos movimentos sociais, aos sindicatos e às instituições de pesquisa. Com esses posicionamentos, demarcamos a importância de conhecer o lugar da avaliação nas propostas em disputa no campo da Educação Infantil e, mais especificamente, as discussões sobre a avaliação institucional, problematizando essas propostas no conjunto de nossas concepções sobre essas questões.

Retomando a década de 1970, no que se refere à avaliação, nesse período o tema passa a ser uma área de muitas práticas e transformase em objeto de estudo. A produção sobre a avaliação aumenta e algumas universidades começam a oferecer cursos de formação em avaliação (DIAS SOBRINHO, 2003). Visto que as lutas relacionadas à educação das crianças menores de sete anos se concentravam na conquista do direito ao acesso e

4 Abordamos questões relacionadas à legislação referente à Educação Infantil na seção seguinte. 
na expansão de vagas, a avaliação ainda não estava incluída nas pautas de discussão, seja na dimensão teórica, seja na dimensão da legislação.

Ao considerar esse percurso histórico compreendido entre as décadas de 1970 e 1980, Dias Sobrinho (2003) afirma ser o período mais consistente, caracterizando-o como um período de profissionalismo da avaliação, diferente de momentos anteriores em que a avaliação assumia outros sentidos, caracterizados em quatro períodos distintos pelo autor. Assim, os estudos focalizavam primordialmente a avaliação da aprendizagem centrada em testes e provas, em uma perspectiva de medida direcionada, então, aos ensinos de $1^{\circ}$ e $2^{\circ}$ graus e ao ensino superior, representando uma herança da nossa colonização (LUCKESI, 1995).

Essa situação pode ser constatada em levantamento bibliográfico realizado por Sousa (2005) em publicações da Fundação Carlos Chagas sobre a avaliação educacional. Nesse trabalho, a autora destaca quatro tendências dominantes no período de 1972 a 2003:

das primeiras publicações até meados de 1980, os trabalhos são, em maior número, direcionados à medida educacional, tratando de processos seletivos/vestibular;

- de meados dos anos de 1970 até início da década de 1980 há, concomitantemente, publicações acerca de avaliação de programas e projetos, no campo da avaliação de currículo;

- a partir de meados de 1985, há publicações relativas à avaliação de políticas educacionais, por meio de apreciação de programas e projetos específicos;

- a partir dos anos iniciais da década de 1980, têm início as publicações que se voltam à avaliação de rendimento escolar, tratando de aspectos relativos à medida de desempenho, exclusivamente ou de modo associado à avaliação de sistemas educacionais, situando-se aí o maior volume de publicações. (SOUSA, 2005, p. 28).

No âmbito da legislação, a elaboração da Constituição Federal, promulgada no fim da década de 1980, integra as discussões paralelas a respeito da formulação da Lei de Diretrizes e Bases da Educação (LDB) de 1996. 
Em conexão com os estudos e pesquisas, Saul (1988), em oposição à avaliação na concepção da lógica do controle, elabora o paradigma da avaliação emancipatória. Esse paradigma dialoga com a proposta de educação crítico-libertadora, incluindo os conceitos de emancipação, decisão democrática, transformação e crítica educativa. Desse modo, na simultaneidade dos acontecimentos (BAKHTIN, 201 l), as lutas e os debates sobre a Educação Infantil e a avaliação institucional não se encontram atrelados a esse momento histórico, haja vista, conforme já assinalado anteriormente, que a prioridade até então era a garantia do acesso.

Em face desse quadro geral da trajetória da educação das crianças de zero a seis anos no Brasil, avançamos para a seção seguinte, dando continuidade à abordagem sobre a Educação Infantil, considerando os avanços na legislação brasileira e enfatizando desafios e perspectivas nesse aspecto.

\section{A EDUCAÇÃO INFANTIL E OS AUANÇOS NA LEGISLAÇÃO}

Na conjuntura política brasileira, a partir de 1990, inicia-se um processo de reestruturação econômica, política e social com base na ideologia neoliberal, tendo as leis do mercado como base para as reformas, em uma lógica de privatização e competitividade, imprimindo formas distintas de representar e valorar o mundo. A consolidação de políticas neoliberais no Brasil atingiu a educação, provocando um processo de sucateamento e privatização, com alterações profundas na docência e nos saberes constituídos, pois "[...] o neoliberalismo precisa - em primeiro lugar, ainda que não unicamente despolitizar a educação, dando-lhe um novo significado como mercadoria para garantir, assim, o triunfo de suas estratégias mercantilizantes e o necessário consenso em torno delas." (GENTILI, 1995, p. 244-245).

No contexto de medidas neoliberais, essa década é marcada também pela implementação das políticas de avaliação em larga escala, tanto no ensino superior quanto na educação básica, conseguindo a Educação Infantil não ser impactada por essas iniciativas. Isso não quer dizer que o tema não estivesse 
presente no campo, mas conseguia mover indicadores mais próprios de sua especificidade, em especial a preocupação com a qualidade.

Em relação aos dados de atendimento, de acordo com o Instituto Nacional de Estudos e Pesquisas Educacionais Anísio Teixeira (Inep), em 1994, do total de 9,9 milhões de crianças de quatro a seis anos, 48\% estavam matriculadas na pré-escola contra apenas 28,6\% em 1985, indicando um crescimento, porém ainda muito distante do atendimento necessário.

Nesse mesmo período de intensas discussões que antecederam a publicação da LDB (BRASIL, 1996), evidenciamos, no documento Política Nacional de Educação Infantil, a preocupação com a qualidade das ações de educação e de cuidado em creches, pois:

Essa expansão, sem os investimentos técnicos e financeiros necessários por parte do Estado e da sociedade, acarretou, em termos globais, uma significativa deterioração na qualidade do atendimento, especialmente na creche. A insuficiência e inadequação de espaços físicos, equipamentos e materiais pedagógicos (especialmente brinquedos e livros); a não incorporação da dimensão educativa nos objetivos da creche; a separação entre as funções de educar e cuidar; a inexistência de currículos e propostas pedagógicas são indicadores importantes da baixa qualidade do atendimento às crianças, especialmente às menores. (BRASIL, 1994, p. 13).

No que concerne à efetivação do direito à educação, embora este tenha sido garantido na Constituição (BRASIL, 1988), passaram-se quase 10 anos até que a LDB (BRASIL, 1996) regulamentasse a Educação Infantil como primeira etapa da educação básica, estabelecendo sua oferta como responsabilidade dos municípios, em regime de colaboração com os estados e a União. Nessa perspectiva, as creches e pré-escolas se desvinculam da assistência social e assumem um novo percurso em sua história, com o desafio de que o atendimento às crianças de zero a seis anos integre o cuidar e o educar.

Na dimensão do financiamento, 11 anos após a promulgação da LDB (BRASIL, 1996), a Educação Infantil passou a receber recursos do Fundo de Manutenção e Desenvolvimento da Educação Básica e de Valorização dos 
Profissionais da Educação (Fundeb) (BRASIL, 2007). Essa inclusão da Educação Infantil no Fundeb exigiu grande organização social, com diversas ações de mobilização coordenadas pela Campanha Nacional pelo Direito à Educação, além da participação de outros movimentos sociais, entre os quais o Movimento Interfóruns de Educação Infantil do Brasil (MIEIB).

Com essa mobilização, a Educação Infantil assegurou sua inserção no Fundeb (BRASIL, 2007), o que representou uma importante conquista sob o aspecto do financiamento educacional no que diz respeito à ampliação do atendimento e à valorização do trabalho docente, visto que o decreto aprovado anteriormente era o Fundo de Manutenção e Desenvolvimento do Ensino Fundamental e de Valorização do Magistério (Fundef) (BRASIL, 1997), que não contemplava a primeira etapa da educação básica.

Um dado que evidencia essa conquista está retratado na Sinopse Estatística da Educação Básica de 1999, que registra um decréscimo de cerca de 200 mil matrículas na pré-escola em 1998 e 159 mil em 1999. As análises de alguns pesquisadores atribuem essa redução à implantação do Fundef, que contemplou unicamente o ensino fundamental. Então, o Fundeb, ao abarcar a Educação Infantil, mobiliza novos recursos, ainda que esses investimentos não consigam responder ao volume das demandas existentes.

Nessa discussão, cabe ressaltar que, antes mesmo da aprovação do Fundeb, com a ampliação do ensino fundamental para nove anos, determinada pela Lei n. 11.274 (BRASIL, 2006b), a Educação Infantil passa a atender às crianças até cinco anos, conforme estabelece a Emenda Constitucional n. 53 (BRASIL, 2006a). Em conformidade com essas medidas, sete anos depois é sancionada a Lei n. 12.796 (BRASIL, 2013) que torna a educação básica gratuita e obrigatória dos quatro aos 17 anos, com prazo até 2016 para que as redes municipais e estaduais cumpram essa regulamentação. Com isso, a universalização é fixada no horizonte do atendimento à Educação Infantil, ainda que impactando apenas a faixa da pré-escola. Tal situação chama a atenção para as demandas da creche, considerando a persistência de indicadores que informam as dificuldades para a expansão do atendimento e a desigualdade presente na sua incipiente faixa de cobertura. 
Com esses desafios presentes, os avanços na legislação garantiram também a construção de novas propostas de gestão e formação de profissionais para o atendimento a essa faixa etária. Tal mudança vem sendo assinalada desde a Constituição Federal de 1988, quando foi reconhecido o papel dos órgãos governamentais no atendimento às crianças de zero a seis anos, a ser exercido do ponto de vista legal pela Educação Infantil em creches e pré-escolas como dever do Estado e um direito da criança. No quadro de pertencimento às redes de ensino, a configuração da Educação Infantil passa a comportar discussões sobre o provimento de pessoal, a articulação com as outras etapas e níveis de ensino, os investimentos necessários à expansão da oferta, entre as muitas pautas em que se articulam suas premissas legais.

No entanto, como sinaliza Kramer (2006), os avanços na legislação educacional e no conhecimento sobre a infância, conquistados pelos movimentos sociais, não foram igualmente acompanhados por alterações nos sistemas educacionais, visto que

[...] na história do atendimento à criança de 0 a 6 anos no Brasil foi constante a criação e extinção de órgãos, superpondo-se programas com mesmas funções. Saúde, assistência e educação não se articularam ao longo da história; ao contrário, o atendimento ramificou-se, sem que uma das esferas se considere responsável. Cada uma das áreas foi apontada como causa, sem uma transformação das condições de vida das crianças. A fragmentação - uma das heranças que recebem as prefeituras - manifesta-se ainda hoje nas suas estratégias de ação. (KRAMER, 2006, p. 779).

Nesse sentido, é necessário o cuidado para não cair na armadilha de desqualificar o aparato legal, visto que ele se constitui um dos mecanismos de luta em direção às conquistas sociais preconizadas. Nesse campo, reiteramos a necessidade de atenção às ameaças de retrocessos nas conquistas previstas nesse aparato legal (ASSOCIAÇÃO NACIONAL DE PÓS-GRADUAÇÃO E PESQUISA EM EDUCAÇÃO, 2016).

De todo modo, como até então apresentado, destacamos que as discussões sobre a Educação Infantil têm ocupado, cada vez mais, espaço no panorama político-educacional brasileiro. Leis, documentos, diretrizes, 
referenciais e políticas nacionais de educação direcionadas às crianças de zero a seis anos foram e estão sendo elaborados, discutindo a finalidade de assegurar à primeira infância o direito à Educação Infantil pública, gratuita e de qualidade. Após três décadas da promulgação da Constituição (BRASIL, 1988) e mais de 20 anos de promulgação da LDB (BRASIL, 1996), ainda existem muitos obstáculos a serem enfrentados pela Educação Infantil. Nas pautas em questão, destaca-se a temática da avaliação, da qual passamos a tratar na próxima seção.

\section{A AUALIAÇÃO INSTITUCIONAL EM MOUIMENTO NA EDUCAÇÃO INFANTIL}

As políticas públicas voltadas à avaliação institucional vêm sendo produzidas há pouco tempo no País, em um cenário marcado por processos de avaliação em larga escala, iniciados na década de 1990, com a implantação do Sistema de Avaliação da Educação Básica (SAEB) pelo Inep. Cabe acentuar que no Plano Nacional de Educação (PNE) 2001-2011, aprovado pela Lei n. 10.172 (BRASIL, 2001), entre as metas e objetivos, encontra-se a previsão de "Estabelecer, nos Municípios, em cinco anos, programas de acompanhamento e avaliação dos estabelecimentos de educação infantil." Esse objetivo não alcançado se mantém no PNE atual (BRASIL, 2014), na estratégia 1.6 referente à meta l, que se direciona simultaneamente à avaliação e à Educação Infantil e estabelece a previsão de

[...] implantar, até o segundo ano da vigência deste PNE, avaliação da educação infantil, a ser realizada a cada dois anos, com base em parâmetros nacionais de qualidade, a fim de aferir a infraestrutura física, o quadro de pessoal, as condições de gestão, os recursos pedagógicos, a situação de acessibilidade, entre outros indicadores relevantes. (BRASIL, 2014, p. 2). 
No que concerne ao PNE atual, essa estratégia permanece sem efetivação, embora uma proposta de avaliação ${ }^{5}$ de contexto na Educação Infantil tenha sido elaborada no período de 2012 e 2015, em uma parceria entre quatro universidades brasileiras e uma universidade italiana.

No tocante às práticas de avaliação de larga escala, faz-se necessário assinalar que, em convergência com políticas econômicas articuladas a organismos internacionais, a definição de determinadas ações avaliativas no Brasil está relacionada aos interesses de cientistas políticos e econômicos. Desse modo, os acontecimentos que circundam a avaliação não ocorrem de forma isolada, tendo em vista a relação existente entre a concepção de sociedade e a prática avaliativa, pois

Há uma intencionalidade nos instrumentos avaliativos frente à ordem social a que se conformam. Dito de forma mais consistente há uma ontologia que os formata e que informa essa intencionalidade. Nas avaliações realizadas se reconhece a sociedade desejada, ou seja, na avaliação se conforma uma determinada visão de mundo. (ZANARDINI, 2008, p. 47).

Desse modo, torna-se premente contextualizar a trajetória da Educação Infantil quanto à produção de documentos oficiais e ordenamentos legais, visto que sua elaboração não se desvincula das políticas vigentes. No entanto, ainda que se relacionem a essa ordem social, também "[...] materializam resistências assumidas durante as últimas décadas por movimentos sociais, docentes, pesquisadores, associações e entidades engajadas com a Educação Infantil." (VIEIRA; CÔCO, 2016).

Sem desconsiderar a importância de todos os documentos produzidos nas últimas décadas e relacionados à etapa inicial da educação básica, em razão do propósito deste artigo, evidenciamos aqueles que mais diretamente se articulam com a avaliação institucional e com a qualidade. Assim, destacamos a publicação do documento Indicadores de Qualidade da Educação Infantil (BRASIL, 2009a), que objetivou detalhar os Parâmetros Nacionais de Qualidade

5 São apresentadas mais informações sobre esse projeto na última seção deste artigo. 
para a Educação Infantil (BRASIL, 2006c) em indicadores com o propósito de “[...] oferecer às equipes de educadores e às comunidades atendidas pelas instituições de educação infantil um instrumento adicional de apoio ao seu trabalho" (BRASIL, 2009a, p. 15), podendo, assim, "auxiliar as equipes, [...] famílias e pessoas da comunidade a participar de processos de autoavaliação da qualidade de creches e pré-escolas [...]" (BRASIL, 2009a, p. 14).

Na processualidade dessa produção, o documento Educação Infantil: Subsídios para a Construção de uma Sistemática de Avaliação propõe uma sistemática avaliativa "que integra fluxos concomitantes e complementares de decisão, procura concretizar a noção de avaliação como um meio que contribui ao propósito mais amplo de melhorar a qualidade de cuidado e educação das crianças." (BRASIL, 2012a, p. 21).

Como nos inspira Bakhtin (201 1), nem a primeira nem a última palavra estão ditas, pois não existem limites para um contexto dialógico, e nossos enunciados estão ligados a outros enunciados, produzindo infinitos sentidos. Assentes nessas premissas, entendemos que a elaboração de documentos no campo da Educação Infantil, mais intensa entre as décadas de 2000 e 2010, vincula-se a enunciados precedentes e simultaneamente movimenta outros diálogos.

Desse ponto de vista, nas pesquisas realizadas na década de 1990, Rocha, Silva Filho e Strenzel (2001) ressaltam duas abordagens de estudos: primeiramente, as pesquisas que buscam estabelecer parâmetros de avaliação da qualidade dos serviços de educação para a criança de zero a seis anos e tomam como referência as experiências nacionais e internacionais; segundo, as pesquisas relacionadas com os distintos tipos de relações estabelecidas no cotidiano dessas instituições, envolvendo os sujeitos (crianças, adultos e todos entre si nas diversas situações) com a família e com o espaço físico. Concordamos com as palavras dos autores ao afirmarem que:

Estas perspectivas indicam alguns esforços no sentido de atender às demandas voltadas para a qualidade da educação das crianças pequenas, de seus profissionais e da sua formação, suscitada especialmente pelo movimento que resultou na promulgação da nova LDB e das normalizações que ela passou a exigir. Desde então temos assistido a uma razoável participação de pesquisadores 
desta área no debate e na crítica dos planos e iniciativas governamentais junto aos órgãos consultivos e deliberativos de âmbito nacional. (ROCHA; SILVA FILHO; STRENZEL, 2001, p. 32).

Tais participações críticas, com análises sobre as iniciativas do Governo, produzem ressonâncias no mundo acadêmico e em diferentes tempos históricos. Nos anos 2009 e 2010, foi realizada uma pesquisa, em seis capitais brasileiras, sobre a qualidade da Educação Infantil no Brasil, em parceria com a Fundação Carlos Chagas, o Ministério da Educação e o Banco Interamericano de Desenvolvimento, envolvendo 147 instituições de Educação Infantil. As análises dos dados evidenciaram que creches e pré-escolas apresentam, em média, níveis de qualidade insatisfatórios. Os níveis mais comprometidos se referem às atividades (creche e pré-escola), rotinas de cuidado pessoal (creche) e estrutura do programa (pré-escola). Mudanças em determinadas características das instituições poderiam levar à melhoria da qualidade da Educação Infantil nos municípios investigados (CAMPOS et al., 2011).

Nessa dinâmica de pesquisas, debates, eventos e articulações políticas, um fato marcou a trajetória da Educação Infantil em 201 l, exigindo posicionamentos de entidades, como a Associação Nacional de Pós-Graduação e Pesquisa em Educação (ANPEd), o Movimento Interfóruns de Educação Infantil do Brasil (MIEIB) e o Fórum Paulista de Educação Infantil (FPEI). Com o objetivo de avaliar as crianças da Educação Infantil, a Secretaria Municipal de Educação do Rio de Janeiro e a Secretaria de Ações Estratégicas do Governo Federal decidiram realizar a aplicação de um questionário com base em um instrumento estadunidense, o Age and Stages Questionnaires (ASQ-3), ${ }^{6}$ visando estabelecer os níveis de desenvolvimento das crianças em todo o País.

Essa iniciativa provocou reações de protesto das entidades engajadas com a defesa dos direitos das crianças pequenas, mobilizando educadores e militantes para manifestarem sua discordância, argumentando, com base na própria trajetória da Educação Infantil, que esse instrumento e

6 O detalhamento desse instrumento pode ser consultado no Manual de Uso do ASQ-3 - guia rápido para aplicação do ASQ-3, divulgado pela Prefeitura Municipal do Rio de Janeiro. Disponível em: <http://200.141.78.79/dlstatic/10112/1132535/DLFE-205901.pdf/1.0>. 
outros procedimentos similares desconsideram as concepções presentes em documentos mandatórios (BRASIL, 1996, 2009b) e orientadores (BRASIL, 2009a), discutidos coletivamente (ANPEd, GT 07 - Educação de crianças de 0 a 6 anos).

Ao formalizar a recusa da aquisição de direitos autorais do instrumento de avaliação americano pelo MEC, a Coordenação Geral de Educação Infantil (Coedi) apresentou as seguintes argumentações:

ministério está criando GT para formulação da política de avaliação da e na Educação Infantil; a definição da política precede a escolha de metodologia e instrumentos; o ASQ-3 não apresenta coerência com a concepção de criança expressa nas Diretrizes Curriculares Nacionais para a Educação Infantil - DCNEI e não se caracteriza como uma metodologia de avaliação da política de Educação Infantil. (BRASIL, 2012a, p. 10).

Em consonância com essa premissa, o documento Educação Infantil: Subsídios para a Construção de uma Sistemática de Avaliação (BRASIL, 2012a), entre os diferentes níveis de prática avaliativa, destaca a importância da avaliação de políticas e de programas de Educação Infantil e reitera a responsabilidade tanto das Secretarias Municipais e Estaduais de Educação quanto do MEC na formulação, implementação e avaliação da Política Municipal destinada a essa etapa.

Nesse quadro de movimentados debates referenciados no documento, a luta segue no intuito de "[...] demarcar uma sistemática que enfatiza a avaliação das condições da oferta de creches/pré-escolas numa perspectiva de avaliação democrática, que respeita e protege direitos das crianças em contextos de desigualdade e diversidade." (VIEIRA, 2014, p. 33). Tal posicionamento, compartilhado por muitos gestores, pesquisadores e ativistas como consenso na área, possibilita a defesa de "[...] que a avaliação na Educação Infantil deve estar centrada nas condições de oferta e, ainda, que o debate precisa avançar no sentido da explicitação de um marco referencial comum para essa avaliação [...]", inclusive enfrentando "[...] o debate acerca da noção de qualidade que será tomada como referência." (BRASIL, 2012, p. 6). 
Contextualizar esse evento de mobilização dos atores sociais comprometidos com os direitos das crianças a uma Educação Infantil de qualidade é necessário para compreendermos os entrelaçamentos e simultaneidades em que distintas disputas ocorrem e para reafirmarmos a importância de acompanhar as proposições, definições e efetivações das ações políticas mais amplas, mantendo-nos alertas para essas movimentações. Acreditando na importância das pesquisas nesse quadro de disputas, compartilhamos, a seguir, algumas experiências de pesquisas empíricas e alguns estudos de caráter bibliográfico sobre a temática da avaliação na Educação Infantil.

Barreto e Novaes (2016), ao realizarem uma retrospectiva das experiências de uso da avaliação institucional na educação básica no Brasil desde meados dos anos 1990, analisam iniciativas de algumas redes de ensino. Nesse registro, ressaltam a experiência da rede estadual do Ceará, realizada entre 1996 e 1999, a da rede municipal de Igrejinha, no Rio Grande do Sul, em 2004, a das escolas estaduais do Paraná, entre 2004 e 2006 e a da rede municipal de Campinas, em 2005. Cabe observar que, embora contemplem a educação básica, somente a experiência de Campinas se direciona à Educação Infantil.

Nesse propósito de desenvolvimento de pesquisas, Moro e Souza (2014) se propõem a mapear ${ }^{7}$ e examinar a produção acadêmica brasileira sobre avaliação em Educação Infantil no período de 1997 a 2012 e assinalam, com base nos dados, que "[...] fica evidente a maior proporção de estudos de contexto na temática da avaliação, o que reafirma a preocupação recente com a interface entre qualidade, educação infantil e avaliação." (MORO; SOUZA, 2014, p. 1 13). Corroborando essa assertiva, Gatti (2014, p. 23) afirma que a política avaliativa tem sido pouco investigada por pesquisadores brasileiros e que "[...] não temos experimentado debates fundamentados e contraposições aos diversos processos avaliativos implementados em vários dos níveis educacionais, a não ser em poucas vozes."

\footnotetext{
7 Esse mapeamento compõe as ações do Projeto de Cooperação Técnica entre a Universidade Federal do Paraná (UFPR) e o MEC, em parceria com UFMG, UFRJ, UDESC e UNIPV/Itália.
} 
$\mathrm{Na}$ esteira de iniciativas de avaliação institucional, destacamos o documento Indicadores da Qualidade na Educação Infantil Paulistana (SÃO PAULO, 2016) como resultado de um processo iniciado na Rede Municipal de São Paulo, em 2013, com a participação, por adesão, de instituições de Educação Infantil "[...] diretas, indiretas e conveniadas da Rede Municipal de Ensino de São Paulo [tendo] como foco o contexto educativo, o que significa que ele visa promover 0 debate sobre as condições necessárias para uma Educação Infantil de qualidade." (SÃO PAULO, 2016, p. 15). Baseado no documento do MEC (BRASIL, 2009a), o instrumento reúne 39 critérios para examinar atividades como a gestão escolar, as experiências e interações que as crianças têm nas unidades, as condições de trabalho dos educadores e a participação da comunidade. Essa avaliação institucional inclui todas as instituições de Educação Infantil da Rede Municipal de São Paulo.

Com base em pesquisa acerca de processos avaliativos, feita em 42 municípios paulistas, Pimenta (2017) constata a preponderância de processos avaliativos direcionados ao desenvolvimento e aprendizagem das crianças, com evidências de iniciativas de processos de autoavaliação institucional articulados com ações de avaliações externas. Focalizando a experiência de um município capixaba, Vieira (2015) analisa o processo de avaliação institucional vivenciado, em 2012, por docentes em duas instituições e evidencia que a avaliação institucional marca um momento significativo de encontro entre as famílias, docentes e demais profissionais para avaliar a qualidade da Educação Infantil.

Nessa conjuntura, destacamos a proposta da Avaliação Nacional da Educação Infantil (ANEI), coordenada pelo MEC, em parceria com o Inep e outros segmentos e em consonância com o PNE, buscando acompanhar a qualidade da oferta da educação para as crianças e possibilitar a realização de avaliação institucional, tendo em vista a compreensão da área de que não devemos realizar a avaliação das crianças da Educação Infantil com base em instrumentos de testes padronizados de desempenho. Em consonância com a concepção de que a avaliação da qualidade precisa se articular com os direitos das crianças, advogamos que "[...] a ANEI chega para responder tanto a exigência estabelecida pela legislação educacional brasileira, como pela 
concepção de que a educação infantil como parte do sistema educacional deve compor um processo de avaliação nacional." (SOUZA, 2015). No processo de regulamentação, a ANEI foi normatizada pela Portaria n. 369 (BRASIL, 2016a), que institui o Sistema Nacional de Avaliação da Educação Básica (Sinaeb) e, no seu art. $8^{\circ}$, define que

[...] a Avaliação Nacional da Educação Infantil, com ciclo avaliativo bianual, a iniciar-se em 2017, com o objetivo de realizar diagnósticos sobre as condições de oferta da educação infantil pelos sistemas de ensino público e privado no Brasil, aferindo a infraestrutura física, o quadro de pessoal, as condições de gestão, os recursos pedagógicos, a situação de acessibilidade, entre outros indicadores contextuais relevantes, além de fornecer subsídios aos sistemas de ensino para a construção de políticas públicas que possibilitem melhoria na qualidade da educação infantil. (BRASIL, 2016a, p. 9).

Essa normatização se manteve vigente apenas por três meses, quando foi revogada pela Portaria n. 981 (BRASIL, 2016b), em decorrência do processo de impeachment da Presidente Dilma Rousseff, ocorrido em agosto de 2016, e a posterior alteração no Governo. Desse modo, permanece uma lacuna quanto à definição de instrumentos, metodologia e sistematização de um processo avaliativo ${ }^{8}$ em consonância com as especificidades da Educação Infantil.

Na dinâmica desses acontecimentos, construindo pontes entre as diferentes temporalidades (BLOCH, 2002), é importante acentuar que a pesquisa sobre a avaliação de contexto que possibilitou a elaboração da ANEI foi desenvolvida em 2012 e 2015, por meio do Projeto de Cooperação Técnica entre a Universidade Federal do Paraná (UFPR) e o MEC, em parceria com UFMG, UFRJ, UDESC e UNIPV/Itália. $\bigcirc$ trabalho vem sendo compartilhado em eventos de pesquisas e em publicações, entre as quais o lançamento do documento Contribuições para a Política Nacional: a avaliação em educação infantil a partir da avaliação de contexto (BRASIL, 2015). Nos estudos realizados,

8 Como medida mais recente, destacamos o Decreto n. 9.342, de 29 de junho de 2018, que regulamenta a Política Nacional de Avaliação e Exames da Educação Básica e em seu Art. $5^{\circ}$ inclui, explicitamente, a Educação Infantil como integrante do Sistema de Avaliação da Educação Básica (SAEB). 
"A perspectiva de avaliação de contexto adotada permite avançar na efetivação de uma participação ativa das profissionais, tendo em vista que todo o processo implica a ação de cada uma para uma dinâmica que é coletiva." (MORO; COUTINHO; BARBOSA, 2017, p. 7).

Diante dos movimentos de produção de pesquisas e documentos em torno da avaliação institucional na Educação Infantil, ressalvamos a importância do contexto político mais amplo e do lugar que a avaliação assume na agenda política e na área da Educação Infantil. Reiterando a palavra como produto da interação do locutor e do ouvinte e território comum entre ambos, concordamos que ela se constitui expressão de um em relação ao outro e também em relação aos grupos em que nos inserimos. Assim, as palavras vão compondo materialidades, desafiando-nos às interações, aos debates, às proposições, enfim, convocando-nos a assumir nossa condição de singularidade e de responsividade para com as questões que nos circundam. Nesse sentido, compartilhamos, a seguir, nossas considerações sobre a temática que optamos por abordar neste texto.

\section{CONSIDERAÇÕES FINAIS}

Em face do contexto dos últimos 40 anos da educação pública brasileira, propusemo-nos, neste artigo, ao diálogo sobre a Educação Infantil em articulação com a avaliação institucional. No propósito de demarcar relevantes momentos em sua trajetória nas últimas décadas, evidenciamos ordenamentos legais, documentos e produções acadêmicas que retratam a complexidade envolvida nos avanços presentes nessa área, em meio a desafios que persistem na garantia de uma Educação Infantil pública, gratuita e de qualidade social para todas as crianças brasileiras. Diante de um conjunto diverso de produções, a interlocução com seus enunciados, por diferentes vias, permitiu-nos tratar a questão da avaliação institucional em uma perspectiva de compreensão histórica dos acontecimentos. 
Lembramos que os fatos, relatos, documentos que tomamos como aportes neste artigo podem já ser de conhecimento dos leitores em sua condição de pesquisadores, militantes e estudiosos da Educação Infantil. Ou seja, não se tratou de revesti-los de um tom de ineditismo, mas de reunir, pela oportunidade apresentada neste dossiê, análises e elementos significativos a partir de um ponto de vista singular que evidencia muitos avanços alcançados nas últimas décadas com as lutas empreendidas pela sociedade civil, professores, familiares, estudiosos da educação e políticos em defesa do direito das crianças à Educação Infantil de qualidade socialmente referenciada.

Nesse sentido, tentamos encontrar conexões entre o passado, o presente e o futuro não somente na dimensão linear ou das relações de causa e efeito, mas também na processualidade dos eventos em seus permanentes movimentos, os quais nos convocam à apropriação dessas dinâmicas e a posicionamentos responsivos.

Assentes nessa premissa de responsividade, se consideramos que a defesa da Educação Infantil busca ser pela qualidade no atendimento às crianças de zero a seis anos e esta requer processos avaliativos, não se pode prescindir da avaliação da Educação Infantil, assim como não se pode abdicar da qualidade. Nessa direção, um dos desafios postos é a consolidação de sistemáticas avaliativas vinculadas às condições ofertadas às crianças e a dinâmicas participativas. Na conjuntura política adversa em que nos encontramos atualmente, as condições de participação em processos decisórios encontramse fragilizadas ante os ditames do autoritarismo que ameaça a sociedade, com graves repercussões nas lutas do campo educacional.

No que tange à avaliação institucional na Educação Infantil, a sistematização deste estudo explicitou que o panorama atual decorre de inúmeros fatos históricos, não se constituindo exclusivamente no bojo das questões educacionais, mas circunscrito à história das crianças, das famílias trabalhadoras, da formação docente, das políticas públicas, de determinantes econômicos e sociais, entre outros elementos. Assinalamos, ainda, a necessidade de considerar o conjunto das mudanças sociais, econômicas, políticas, culturais e epistemológicas, no intuito de encontrar alternativas de continuidade de 
mobilização para a garantia da premissa da educação como um direito de todos.

Reconhecemos que ainda há um longo caminho a percorrer para que, de fato, todos os direitos conquistados legalmente se consolidem. Acreditamos que as intensas mudanças sociais e políticas das últimas décadas, compartilhadas pela oportunidade desta produção dialógica, corroborem a relevância de nos mantermos nesse caminho que se compõe de avanços, disputas, desafios e perspectivas.

Finalizamos este texto sem, contudo, encerrar o diálogo, reiterando o convite à continuidade das interlocuções acerca da Educação Infantil em sua articulação com a avaliação institucional, especialmente na tensão entre a afirmação da importância da avaliação de contexto e os riscos de encaminhar políticas de avaliação direcionadas às crianças. Na continuidade da luta por uma avaliação que se some à busca por garantir a oferta de uma educação de qualidade na Educação Infantil, ficamos na expectativa das contrapalavras no intento de continuar a mover essa cadeia dialógica.

\section{REFERÊNCIAS}

ASSOCIAÇÃO NACIONAL DE PÓS-GRADUAÇÃO E PESQUISA EM EDUCAÇÃO. Boletim Especial Conquistas em Risco, ano 5, n. 20, maio 2016. Disponível em: <http://www.anped.org.br/news/boletim-anped-maio-de-2016-especial-conquistas-em-risco>. Acesso em: 18 jun. 2016.

BAKHTIN, M. M. Estética da criação verbal. Tradução Paulo Bezerra. 6. ed. São Paulo: Martins Fontes, 2011.

BARRETTO, E. de Sá; NOVAES, G. T. F. Avaliação institucional na educação básica: retrospectiva e questionamentos. Estudos em Avaliação Educacional, São Paulo, v. 27, n. 65, p. 314-345, maio/ago. 2016. Disponível em: <http://publicacoes.fcc.org.br/ojs/index.php/eae/article/view/3839/3192>. Acesso em: 21 dez. 2017.

BL○CH, M. Apologia da História ou o Ofício do Historiador. Rio de Janeiro: Jorge Zahar Editor, 2002. 
BRASIL. Constituição. República Federativa do Brasil de 1988. Brasília, DF: Senado Federal, 1988.

BRASIL. Contribuições para a Política Nacional: a avaliação em educação infantil a partir da avaliação de contexto. Curitiba: Imprensa/UFPR; Braślia, DF: MEC/SEB/COEDI, 2015. Disponível em: <http://primeirainfancia.org.br/ wp-content/uploads/2016/04/seb_avaliacao_educacao_infantil_a_partir_avaliacao_contexto.pdf>. Acesso em: $\overline{1} 7$ nov. $20 \overline{1} 7$.

BRASIL. Emenda Constitucional n. 53, de 19 de dezembro de 2006. Dá nova redação aos arts. $7^{\circ}$, 23, 30, 206, 208, 211 e 212 da Constituição Federal e ao art. 60 do Ato das Disposições Constitucionais Transitórias. Diário Oficial da União, Brasília, DF, 19 dez. 2006a. Disponível em: < http://www.planalto. gov.br/ccivil_03/constituicao/emendas/emc/emc53.htm>. Acesso em: 23 jun. 2017.

BRASIL. Decreto n. 2.264, de 27 de junho de 1997. Diário Oficial da União, Brasília, DF, 1997. Disponível em: <http://www2.camara.leg.br/legin/fed/ decret/1997/decreto-2264-27-junho-1997-445021-publicacaooriginal-1-pe. html >. Acesso em: 19 out. 2013.

BRASIL. Educação Infantil: subsídios para construção de uma sistemática de avaliação. Brasília, DF: MEC/SEB, 2012a. Disponível em: <portal.mec.gov.br/ index.php?option=com_docman\&task... >. Acesso em: 29 jun. 2013.

BRASIL. Indicadores da qualidade na educação infantil. Brasília, DF: MEC/ SEB, 2009a. Disponível em: <http://www.portal.mec.gov.br/dmdocuments/ indic_educ_infantil.pdf>. Acesso em: 05 maio 2013.

BRASIL. Lei n. 5.692, de 11 de agosto de 1971. Fixa Diretrizes e Bases para o ensino de $1 .^{\circ}$ e $2 .^{\circ}$ graus, e dá outras providências. Diário Oficial da União, Brasília, DF, 11 ago. 1971. Disponível em: <http://www.planalto.gov.br/ccivil_03/Leis/L5692.htm>. Acesso em: 12 nov. 2017.

BRASIL. Lei n. 9.394, de 20 de dezembro de 1996. Fixa as diretrizes e bases da educação nacional. Diário Oficial da União, Brasília, DF, 23 dez. 1996. Disponível em: < portal.mec.gov.br/arquivos/pdf/ldb.pdf>. Acesso em: 16 jul. 2013.

BRASIL. Lei 10.172, de 09 de janeiro de 2001. Institui o Plano Nacional de Educação e dá outras providências. Diário Oficial da União, Brasília, DF, 09 jan. 2001. Disponível em: <http://www.planalto.gov.br/ccivil_03/leis/ leis 2001/110172.htm>. Acesso em: 15 set. 2013. 
BRASIL. Lei n. 1 1.274, de 06 de fevereiro de 2006. Altera a redação dos arts. 29, 30, 32 e 87 da Lei no 9.394, de 20 de dezembro de 1996, que estabelece as diretrizes e bases da educação nacional, dispondo sobre a duração de 9 (nove) anos para o ensino fundamental, com matrícula obrigatória a partir dos 6 (seis) anos de idade. Diário Oficial da União, Brasília, DF, 2006b. Disponível em: <http://www.planalto.gov.br/ccivil_03/_Ato2004-2006/2006/Lei/ Ll 1274.htm>. Acesso em: 26 mar. 2013.

BRASIL. Lei n. 1 1.494, de 20 de junho de 2007. Diário Oficial da União, Brasília, DF, 14 nov. 2007. Disponível em: < http://www.planalto.gov.br/ccivil_03/_ato2007-2010/2007/lei/l1 1494.htm>. Acesso em: 19 out. 2012.

BRASIL. Lei n. 12.796, de 04 de abril de 2013. Altera a Lei n. 9.394, de 20 de dezembro de 1996, que estabelece as diretrizes e bases da educação nacional, para dispor sobre a formação dos profissionais da educação e dar outras providências. Diário Oficial da União, Brasília, DF, 04 abr. 2013. Disponível em: <http://www.planalto.gov.br/ccivil_03/_Ato201 1-2014/2013/Lei/L12796. htm>. Acesso em: 14 nov. 2018.

BRASIL. Lei n. 13.005, de 25 de junho de 2014. Institui o Plano Nacional de Educação e dá outras providências. Diário Oficial da União, Brasília, DF, 26 jun. 2014. Disponível em: <http://www.planalto.gov.br/legislacao>. Acesso em: 27 jun. 2014.

BRASIL. Parâmetros nacionais de qualidade para a Educação Infantil. Brasília, DF: MEC/SEB, 2006c. Disponível em: < portal.mec.gov.br/index. php?option=com_content\&id=16478 ... . Acesso em: 19 out. 2013.

BRASIL. Política Nacional de Educação Infantil. Brasília, DF: MEC/SEB, 1994. Disponível em: <http://www.dominiopublico.gov.br/download/texto/ me002610.pdf >. Acesso em: 13 mar. 2013.

BRASIL. Portaria n. 369, de 06 de junho de 2016. Institui o Sistema Nacional de Avaliação da Educação Básica (SINAEB). Diário Oficial da União, Brasília, DF, 07 jun. 2016a. Disponível em: <http://www.imprensanacional.gov.br/ materia/-/asset_publisher/KujrwOTZC2Mb/content/id/19628396/dol-201806-07-portaria-n-369-de-6-de-junho-de-2018-19628217 > . Acesso em: 17 nov. 2017. 
BRASIL Portaria n. 981, de 25 de agosto de 2016. Revoga a Portaria MEC n. 369, de 05 de maio de 2016, e dá outras providências. Diário Oficial da União, Brasília, DF, 26 ago. 2016b. Disponível em: <http://portal.mec.gov. $\mathrm{br} /$ index . php?option $=\mathrm{com}$ docman\&view $=$ download\&alias $=4762 \mathrm{l}$-portaria-981-02set-pdf\&category_slug=agosto-2016-pdf\&Itemid=30192> . Acesso em: 17 nov. 2017.

BRASIL. Resolução n. 05, de 17 de dezembro de 2009. Fixa as diretrizes curriculares nacionais para a Educação Infantil. Diário Oficial da União, Brasília, DF, 18 dez. 2009b. Disponível em: < portal.mec.gov.br/index. php?option=com_docman\&task $>$. Acesso em: 16 jul. 2013.

CAMPOS, M. M. Entre as políticas de qualidade e a qualidade das práticas. Cadernos de Pesquisa, São Paulo, v. 43, n. 148, p. 22-43, jan./abr. 2013. Disponível em: <http://www.scielo.br/pdf/cp/v43nl48/03.pdf>. Acesso em: 02 jul. 2013.

CAMPOS, M. M. et al. A qualidade da educação infantil: um estudo em seis capitais brasileiras. Cadernos de Pesquisa, São Paulo, v. 41 , n. 142 jan./abr. 201 l. Disponível em: <http://www.scielo.br/pdf/cp/v4lnl42/v4lnl42a03. pdf $>$. Acesso em: 12 fev. 2013.

DIAS SOBRINHO, J. Avaliação: políticas educacionais e reformas da educação superior. São Paulo: Cortez, 2003.

GATTI, B. A. Avaliação: contexto, história e perspectivas. Olhares, Guarulhos, v. 2, n. 1, p. 8-26, maio 2014. Disponível em: <http://olhares.unifesp.br/index.php/olhares/article/viewFile/202/76 > . Acesso em: 17 nov. 2017.

GENTILLI, P. A. A. Pedagogia da exclusão. Petrópolis: Vozes, 1995.

KRAMER, S. A política do pré-escolar no Brasil: a arte do disfarce. 5. ed. São Paulo: Cortez, 1995.

KRAMER, S. As crianças de 0 a 6 anos nas políticas educacionais no Brasil: educação infantil e/é fundamental. Educação e Sociedade, Campinas, v. 27, n. 96, p. 797-818, out. 2006. Edição especial. Disponível em: <http://www. scielo.br/pdf/es/v27n96/a09v2796.pdf>. Acesso em: 23 nov. 2017.

KUHLMANN JÚNIOR, M. Histórias da educação infantil brasileira. Revista Brasileira de Educação, São Paulo, n. 14, maio/ago. 2000. Disponível em: <www.scielo.br/pdf/rbedu/nl4/n14a02>. Acesso em: 25 maio 2014.

LUCKESI, C. C. Avaliação da aprendizagem escolar: estudos e proposições. 2. ed. São Paulo: Cortez, 1995. 
MORO, C.; COUTINHO, Â. M. S.; BARBOSA, E. B. L. Avaliação de Contexto em Educação Infantil: a participação e o protagonismo docente. Revista Latinoamericana de Educación Infantil, v. 6, n. 1-2 2017. Disponível em: $<$ http://redaberta.usc.es/reladei/index.php/reladei/issue/view/23/showToc $>$. Acesso em: 12 jan. 2018.

MORO, C. de S.; SOUZA, G. de. Produção acadêmica brasileira sobre avaliação em educação infantil: primeiras aproximações. Estudos em Avaliação Educacional, São Paulo, v. 25, n. 58, p. 100-125, maio/ago. 2014. Disponível em: <http://www.fcc.org.br/pesquisa/publicacoes/eae/arquivos/1928/1928. pdf $>$. Acesso em: 24 fev. 2015.

OLIVEIRA, M. M. de. Florestan Fernandes. Recife: Fundação Joaquim Nabuco, Editora Massangana, 2010. Coleção Educadores. Disponível em: < http:// www.dominiopublico.gov.br/download/texto/me4699.pdf>. Acesso em: 18 nov. 2017.

PIMENTA, C. O. Avaliações municipais da educação infantil: contribuições para a garantia do direito à educação das crianças brasileiras? 652 p. Tese (Doutorado)-Faculdade de Educação, Universidade de São Paulo, São Paulo, 2017. Disponível em: <http://www.teses.usp.br/teses/disponiveis/48/48134/ tde-23082017-105049/pt-br.php>. Acesso em: 19 out. 2017.

ROCHA, E. A. C.; SILVA FILHO, J. J. da; STRENZEL, G. R. Estado do Conhecimento, n. 2, Brasília, DF: MEC/Inep/Comped, 2001. Disponível em: <http:// download.inep.gov.br/download/cibec/200l/estado_do_conhecimento/serie_doc_educeduc_infantil.pdf $>$. Acesso em: 28 jun. $\overline{201 \overline{3}}$.

ROSEMBERG, F. A educação pré-escolar brasileira durante os governos militares. Cadernos de Pesquisa, São Paulo, n. 82, p. 21-30, ago. 1992. Disponível em: <http://publicacoes.fcc.org.br/ojs/index.php/cp/article/ view/979/989>. Acesso em: 17 nov. 2017.

ROSEMBERG, F. Avaliação de programas, indicadores e projetos em educaÇão infantil. Revista Brasileira de Educação, n. 16, p. 19-26, 2001 . Disponível em: <http://www.scielo.br/pdf/rbedu/n16/n16a02.pdf>. Acesso em: 12 out. 2013.

ROSEMBERG, F. Políticas de educação infantil e avaliação. Cadernos de Pesquisa, São Paulo, v. 43, n. 148, p. 16-21, jan./abr. 2013. Disponível em: $<$ http//www.scielo.br/scielo.php?pid=S0100-15742013000100003...sci...>. Acesso em: 02 jul. 2013. 
ROSEMBERG, F. Sísifo e a educação infantil brasileira. Pro-Posições, Campinas, v. 14, n. 1 (40), p. 177-194, jan./abr. 2003. Disponível em: <http://www. proposicoes.fe.unicamp.br/proposicoes/textos/40-artigos-rosembergf.pdf > . Acesso em: 10 jan. 2015.

RUIZ, M. J. F. Proletarização do magistério e lutas pela educação no estado do Paraná: do regime militar à ascensão do neoliberalismo (1960-1990). Roteiro, Joaçaba, v. 38, n. 2, p. 233-256, jul./dez. 2013. Disponível em: <http://editora.unoesc.edu.br/index.php/roteiro/article/view/2790>. Acesso em: 25 nov. 2017.

\section{SÃO PAULO (Município). Indicadores de Qualidade da Educação Infantil}

Paulistana. São Paulo: SME/DOT, 2016. Disponível em: <http://www.sinesp. org.br/images/9_ INDICADORES_DE_QUALIDADE_NA_EDUCACAO_INFANTIL_PAULISTĀNA A.pdf $>$. Acesso em: 17 nov. $201 \overline{7}$.

SAUL, A. M. Avaliação emancipatória: desafio à teoria e à prática de avaliação e reformulação de currículo. São Paulo: Cortez, 1988.

SOUSA, S. M. Z. L. 40 anos de contribuição à Avaliação Educacional. Estudos em Avaliação Educacional, São Paulo, v. 16, n. 31, jan./jun. 2005. Disponível em: < http://publicacoes.fcc.org.br/ojs/index.php/eae/article/ view/2140/2097>. Acesso em: 10 nov. 2017.

SOUZA, Gizele de. ANEI e Educação Infantil. Rio de Janeiro, 01 set. 2015. Entrevista concedida à Associação Nacional de Pós-Graduação e Pesquisa em Educação. Disponível em: <http://www.anped.org.br/news/anei-e-educacao-infantil-entrevista-com-gizele-de-souza-gt-07>. Acesso em: 08 nov. 2017.

VIEIRA, L. F. Apontamentos sobre o documento "Educação infantil: subsídios para a construção de uma sistemática de avaliação". Nuances: estudos sobre Educação, Presidente Prudente, v. 25, n. 3, p. 18-35, set./dez. 2014. Disponível em: <http://revista.fct.unesp.br/index.php/Nuances/article/viewFile/3166/2704>. Acesso em: 18 fev. 2015.

VIEIRA, M. N. de A. Avaliação institucional na Educação Infantil: percursos formativos. 2015. 254 p. Dissertação (Mestrado)_Universidade Federal do Espírito Santo, Vitória, 2015. Disponível em: <http://repositorio.ufes.br/bitstream/10/2464/1/tese_9022_Nilceia\%20.pdf>. Acesso em: 22 dez. 2015.

VIEIRA, M. N. de A.; CÔCO, V. Avaliação e Currículo na Educação Básica: a especificidade da Educação Infantil. Práxis Educativa, Ponta Grossa, v. 11 , n. 3, p. 812-831, set./dez. 2016. Disponível em: <http://www.revistas2.uepg. br/index.php/praxiseducativa >. Acesso em: 14 fev. 2017. 


\section{ZANARDINI, J. B. Ontologia e avaliação da educação básica no Brasil}

(1990-2007). 2008. 208 p. Tese (Doutorado)-Faculdade de Educação, Universidade Federal de Santa Catarina, Santa Catarina, 2008. Disponível em: < http://www.repositorio.ufsc.br/handle/123456789/91269>. Acesso em: 02 jul. 2013.

Recebido em 30 de janeiro de 2018 Aceito em 18 de julho de 2018

Endereços para correspondência: Rua Ignacio Higino, 1 170, apto 601-B, Praia da Costa, 29101-094, Vila Velha, Espírito Santo, Brasil; nilceia_vilavelha@hotmail.com 